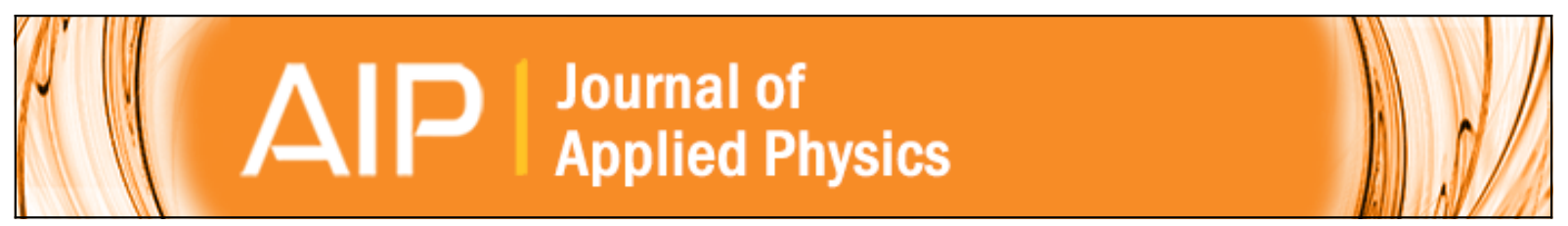

\title{
Effects of deposition rate on the structure and electron density of evaporated BaSi2
}

\section{films}

Kosuke O. Hara, Cham Thi Trinh, Keisuke Arimoto, Junji Yamanaka, Kiyokazu Nakagawa, Yasuyoshi Kurokawa

, Takashi Suemasu, and Noritaka Usami

Citation: Journal of Applied Physics 120, 045103 (2016); doi: 10.1063/1.4959214

View online: http://dx.doi.org/10.1063/1.4959214

View Table of Contents: http://scitation.aip.org/content/aip/journal/jap/120/4?ver=pdfcov

Published by the AIP Publishing

\section{Articles you may be interested in}

Pulsed laser deposition of highly oriented stoichiometric thin films of topological insulator Sb2Te3

J. Vac. Sci. Technol. B 34, 021806 (2016); 10.1116/1.4943026

Electrical and optical properties of transparent conducting In4+xSn3-2xSbxO12 thin films

J. Appl. Phys. 110, 033702 (2011); 10.1063/1.3605552

Electrostatic quadrupole plasma mass spectrometer measurements during thin film depositions using simultaneous matrix assisted pulsed laser evaporation and magnetron sputtering

J. Vac. Sci. Technol. A 28, 419 (2010); 10.1116/1.3372401

Deposition of silicon carbide films using a high vacuum metalorganic chemical vapor deposition method with a single source precursor: Study of their structural properties

J. Vac. Sci. Technol. B 22, 2216 (2004); 10.1116/1.1775191

Epitaxial growth of wurtzite $\mathrm{GaN}$ on $\mathrm{Si}(111)$ by a vacuum reactive evaporation

J. Appl. Phys. 87, 2830 (2000); 10.1063/1.372264

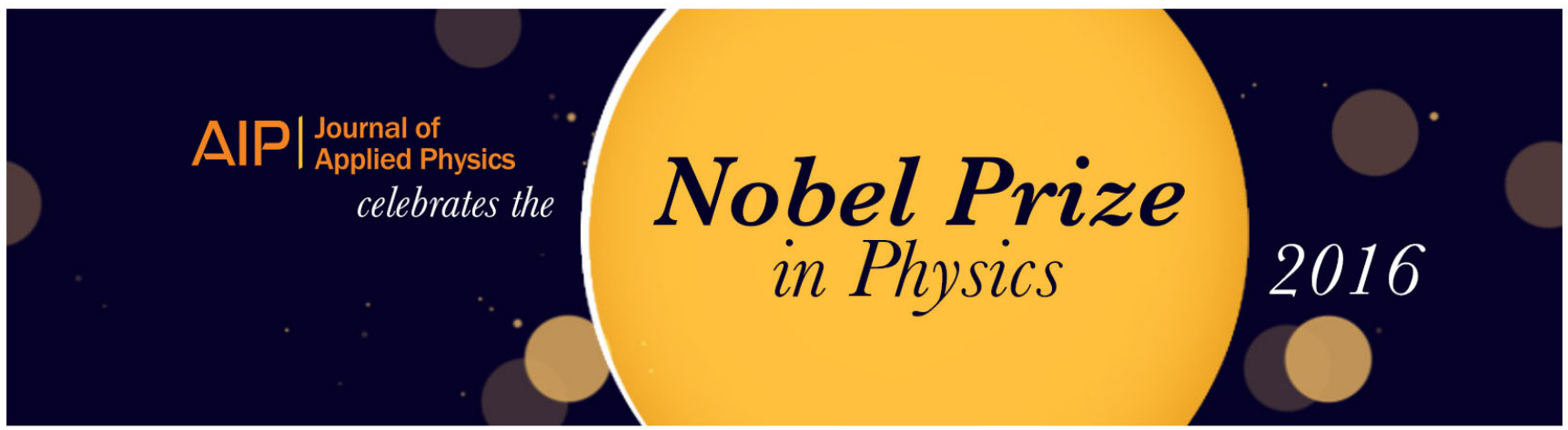




\title{
Effects of deposition rate on the structure and electron density of evaporated $\mathrm{BaSi}_{2}$ films
}

\author{
Kosuke O. Hara, ${ }^{1, a)}$ Cham Thi Trinh, ${ }^{2}$ Keisuke Arimoto, ${ }^{1}$ Junji Yamanaka, ${ }^{1}$ \\ Kiyokazu Nakagawa, ${ }^{1}$ Yasuyoshi Kurokawa, ${ }^{2}$ Takashi Suemasu, ${ }^{3}$ and Noritaka Usami ${ }^{2}$ \\ ${ }^{1}$ Center for Crystal Science and Technology, University of Yamanashi, Kofu, Yamanashi 400-8511, Japan \\ ${ }^{2}$ Graduate School of Engineering, Nagoya University, Nagoya 464-8603, Japan \\ ${ }^{3}$ Institute of Applied Physics, University of Tsukuba, Tsukuba, Ibaraki 305-8573, Japan
}

(Received 10 March 2016; accepted 9 July 2016; published online 22 July 2016)

\begin{abstract}
In order to control the electrical properties of an evaporated $\mathrm{BaSi}_{2}$ film, which is an emerging candidate for the absorber-layer material of earth-abundant thin-film solar cells, we have investigated the effects of deposition rate on the produced phases, microstructure, and carrier density of the thin films grown by thermal evaporation of $\mathrm{BaSi}_{2}$. X-ray diffraction results show that a high substrate temperature is necessary for $\mathrm{BaSi}_{2}$ formation at a high deposition rate, which is discussed from viewpoints of vapor composition and diffusion time. Microstructural characteristics such as grain size of $30-120 \mathrm{~nm}$, oxide particle arrays present around the interface, and partial oxidation at a low substrate temperature are revealed by cross-sectional transmission electron microscopy, X-ray photoelectron spectroscopy, and scanning electron microscopy combined with an energy-dispersive X-ray spectroscopy. With increasing deposition rate, the crystalline quality of $\mathrm{BaSi}_{2}$ is found to improve, as evidenced by a decrease in full-width at half maximum of a $\left[\mathrm{Si}_{4}\right]^{4-}$ vibration band in Raman spectra. At the same time, electron density, which is determined by Hall measurement, decreases with deposition rate. The variation of electron density is discussed on the basis of microstructural characteristics and $\mathrm{BaSi}_{2}$ formation mechanism. The most probable reason is concluded to be composition deviation from stoichiometry. Published by AIP Publishing. [http://dx.doi.org/10.1063/1.4959214]
\end{abstract}

\section{INTRODUCTION}

The $\mathrm{BaSi}_{2}$ semiconductor is attracting much attention as an alternative candidate for the absorber layer of thin-film solar cells because of potential high efficiency as well as the abundance of constituent elements in the earth's crust. Recent extensive studies have shown that $\mathrm{BaSi}_{2}$ has excellent optoelectronic properties for photovoltaic applications including an appropriate band gap of $1.1-1.3 \mathrm{eV},{ }^{1-5}$ high optical absorption coefficients $\left(>10^{4} \mathrm{~cm}^{-1}\right.$ for a photon energy of $>1.4 \mathrm{eV}),{ }^{3-6}$ and long minority-carrier diffusion length $(10 \mu \mathrm{m})^{7}$ and lifetime (up to $11 \mu \mathrm{s}$ ). ${ }^{8}$ In addition, the control of carrier type and density is possible by impurity doping. ${ }^{9-16}$ For $2-\mu$ m-thick $\mathrm{BaSi}_{2}$ homojunction diodes, a photoconversion efficiency of $25 \%$ is expected under ideal conditions. ${ }^{17}$

$\mathrm{BaSi}_{2}$ epitaxial films can be grown on $\mathrm{Si}$ substrates by molecular beam epitaxy, ${ }^{18,19}$ and have been used for fundamental studies. For practical applications, however, a more simple and high-speed process is favorable. We are therefore developing a thermal evaporation technique for $\mathrm{BaSi}_{2}$. So far, we have realized $\mathrm{BaSi}_{2}$ films on various substrates such as silicon, ${ }^{20}$ glass, ${ }^{5}$ and $\mathrm{CaF}_{2},{ }^{21}$ and have revealed the $\mathrm{BaSi}_{2}$ formation mechanism. ${ }^{5,20,22,23}$ The composition of the vapor produced from $\mathrm{BaSi}_{2}$ by thermal evaporation is Ba-rich in the initial stage and it changes to Si-rich as evaporation proceeds. ${ }^{20}$ And, in average, vapor composition is Ba-rich. ${ }^{5}$ For the formation of homogeneous $\mathrm{BaSi}_{2}$ layer, therefore, atomic

\footnotetext{
a) Author to whom correspondence should be addressed. Electronic mail: khara@yamanashi.ac.jp.
}

diffusion and the reaction between excess $\mathrm{Ba}$ atoms and $\mathrm{Si}$ substrate are essential processes. ${ }^{5,20}$ In fact, it has been demonstrated that a high growth temperature is necessary to promote diffusion for the formation of thick $\mathrm{BaSi}_{2}$ films. ${ }^{22}$ Here, deposition rate is presumably another critical parameter influencing the time and extent of the diffusion of deposited atoms and the $\mathrm{Ba}-\mathrm{Si}$ reaction. Effects of deposition rate on the thermal evaporation process of $\mathrm{BaSi}_{2}$ has, however, not been investigated so far.

For electrical characterization, we have previously prepared evaporated $\mathrm{BaSi}_{2}$ films on an insulating $\mathrm{CaF}_{2}$ substrate. ${ }^{21}$ Determined carrier (electron) density was very high $\left.\left(6 \times 10^{20} \mathrm{~cm}^{-3}\right)\right)^{21}$ For absorber-layer applications, it is essential to lower and control the carrier density. In the previous study, ${ }^{21}$ we also found that a pre-deposited amorphous Si layer, which was needed to control stoichiometry, brought about a defective $\mathrm{BaSi}_{2}$ layer with small grain size in the bottom part of the film, which may be one reason of high carrier density. On the other hand, on a $\mathrm{Si}$ substrate, a $\mathrm{Si}$ supply layer is not necessary and the crystalline quality of $\mathrm{BaSi}_{2}$ is better. ${ }^{20}$ In this study, therefore, we focus on the electrical properties of evaporated $\mathrm{BaSi}_{2}$ films grown on the Si substrates. Electrical properties may also be modified when the film structure is modified by deposition rate. Thus, the purpose of the present study is to reveal the effects of deposition rate on the structure and electrical properties of the thin films fabricated by thermal evaporation of $\mathrm{BaSi}_{2}$ on $\mathrm{Si}$ substrates. The $\mathrm{BaSi}_{2}$ formation window is revealed by structural characterization, which supports the $\mathrm{BaSi}_{2}$ formation mechanism previously proposed by us. ${ }^{5,20,22,23}$ The microstructure of the 
$\mathrm{BaSi}_{2}$ films is also elucidated. Moreover, electrical characterization reveals a decreasing trend of electron density with increasing deposition rate, which will be discussed in terms of defects and impurities.

\section{EXPERIMENTAL METHODS}

We used commercial $\mathrm{BaSi}_{2}$ lumps (99\% in purity, Kojundo Chemical, Ltd.) as a source material for thermal evaporation. The $\mathrm{BaSi}_{2}$ lumps were ground into granules of a few millimeters and several of them were placed on a tungsten boat in a high-vacuum chamber. The granules were then melted by resistive heating of the boat and the vapor was deposited on the p-type $\mathrm{Si}(100)$ substrate placed by $15 \mathrm{~cm}$ apart from the source. The base pressure of the chamber was below $1 \times 10^{-3} \mathrm{~Pa}$. We used two kinds of boron-doped $\mathrm{p}$ $\operatorname{Si}(100)$ substrates with different resistivities of $\geq 1000$ and 1-30 $\Omega \mathrm{cm}$ to discuss the accuracy of Hall measurement. The Si substrates were cleaned by organic solvents (acetone and methanol) followed by $2.5 \% \mathrm{HF}$ solution for $1 \mathrm{~min}$ before usage. Removal of the native oxide layer was confirmed by observing the hydrophobic nature of the surface. Substrate temperature $\left(T_{\text {sub }}\right)$ was varied in a range of $550-650^{\circ} \mathrm{C}$. By raising the heating current of boat, one can observe with one's eyes that the $\mathrm{BaSi}_{2}$ source melts and gradually disappears. We opened the substrate shutter just before rapidly raising the heating current for evaporation and closed it just after the disappearance of melt. Average deposition rate $(R)$ was calculated by dividing the film thickness by the period of shutter open. $R$ was changed in a range of $64-2800 \mathrm{~nm} / \mathrm{min}$ by the heating current. Let us note that the evaporator used in this study is different from that in our previous studies. ${ }^{5,20,21}$

The structure of fabricated films was characterized by grazing-incidence X-ray diffraction (XRD; Bruker Discover D8) with $\mathrm{Cu} \mathrm{K} \alpha$ radiation, Raman spectroscopy (Renishaw inVia Raman microscope) with a diode laser $(\lambda=488 \mathrm{~nm})$, scanning electron microscopy (SEM; JEOL JSM-7001FA) with energy-dispersive X-ray spectroscopy (EDX) system, transmission electron microscopy (TEM; Hitachi $\mathrm{H}$ 9000NAR and HD-2700), and X-ray photoelectron spectroscopy (XPS; JEOL JPS-9200) with monochromated Al $\mathrm{K} \alpha$ radiation. SEM-EDX was operated at an acceleration voltage of 5 or $15 \mathrm{kV}$. Bright- and dark-field TEM images were recorded at an acceleration voltage of $300 \mathrm{kV}$ while high-angle annular dark-field scanning transmission electron microscopy (HAADF-STEM) images were obtained at $200 \mathrm{kV}$. Depth profiles of XPS spectra were measured by sputtering the sample with $\mathrm{Ar}^{+}$ions. In order to take into account the charging effects in the probably insulating surface oxide layer, the XPS spectra from the surface were referred to the $\mathrm{C} 1 s$ core-level line $(284.6 \mathrm{eV})$, which was present as contaminant. Electrical properties were analyzed by Hall measurement (TOYO ResiTest8308) with the van der Pauw method. For the Hall measurement, 100-nm-thick $\mathrm{Al}$ ohmic contacts were formed on the film surface by sputtering. Deposition rate of $\mathrm{Al}$ was $5 \mathrm{~nm} / \mathrm{min}$ and no intermediate layers were used for adhesion.

\section{RESULTS AND DISCUSSION}

\section{A. $\mathrm{BaSi}_{2}$ formation window}

Figure 1 shows the XRD patterns of the evaporated films deposited at $T_{\text {sub }}=550$ and $650{ }^{\circ} \mathrm{C}$ and $R=64$ and $840 \mathrm{~nm} /$ min. At $650^{\circ} \mathrm{C}$ [Figs. 1(a) and 1(b)], all peaks are attributed to orthorhombic $\mathrm{BaSi}_{2}$ phase, indicating the formation of single-phase $\mathrm{BaSi}_{2}$ films, regardless of $R$. On the other hand, at $550{ }^{\circ} \mathrm{C}$, produced phases depend on $R$. At a low $R$ value of $64 \mathrm{~nm} / \mathrm{min}$, only $\mathrm{BaSi}_{2}$ diffraction peaks are observed while $\mathrm{BaSi}$ and $\mathrm{Ba}_{5} \mathrm{Si}_{3}$ coexist with $\mathrm{BaSi}_{2}$ at $R=840 \mathrm{~nm} / \mathrm{min}$. Also at $R=200 \mathrm{~nm} / \mathrm{min}$ (not shown), a mixture of $\mathrm{BaSi}_{2}, \mathrm{BaSi}$, and $\mathrm{Ba}_{5} \mathrm{Si}_{3}$ was produced although the amount of subsilicides seem to be smaller than at $R=840 \mathrm{~nm} / \mathrm{min}$. Thus, it is found that a high $T_{\text {sub }}$ is necessary for high-speed growth of $\mathrm{BaSi}_{2}$ films.

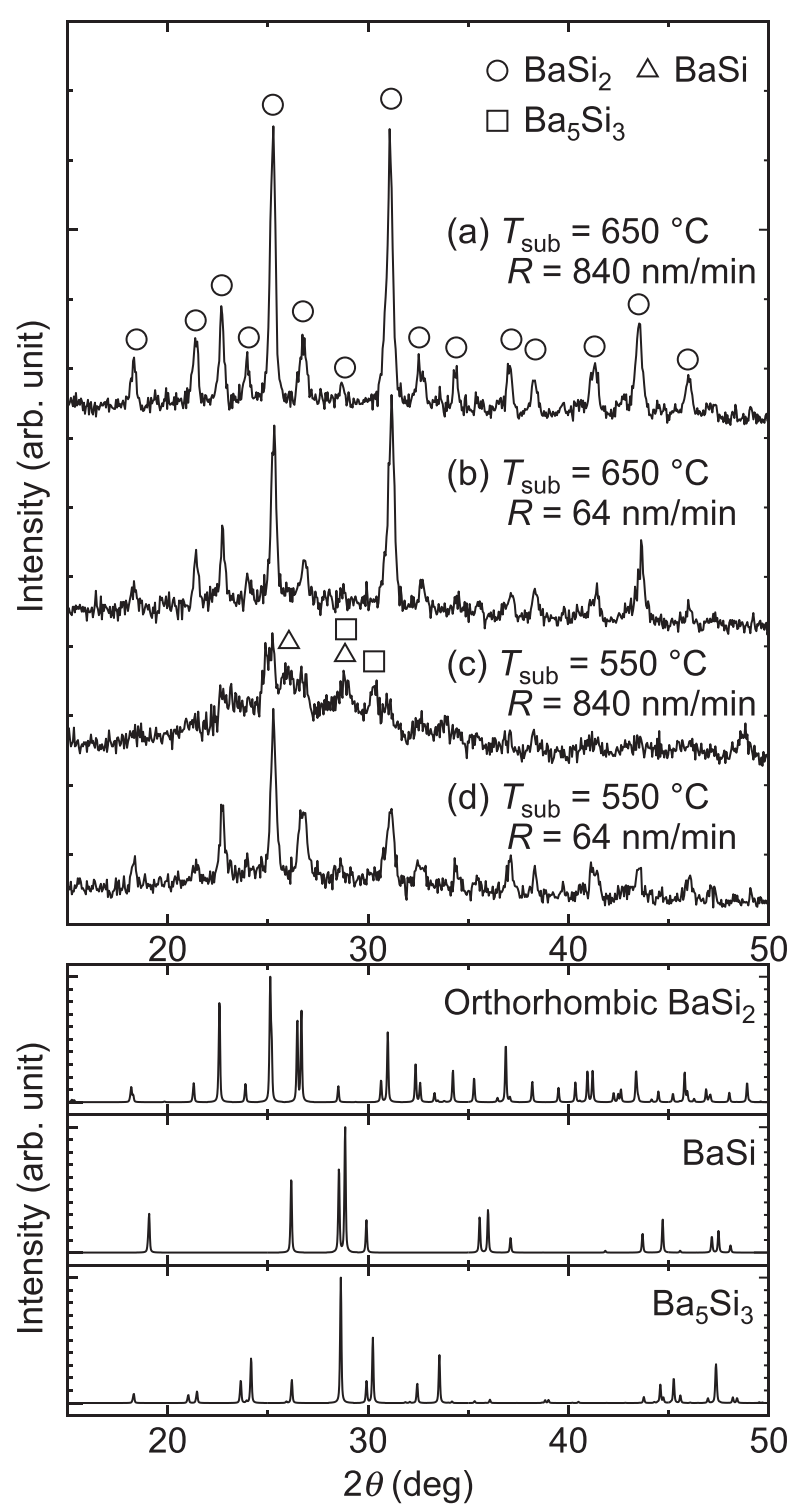

FIG. 1. XRD patterns of the evaporated films grown at (a) $T_{\text {sub }}=650^{\circ} \mathrm{C}$ and $R=840 \mathrm{~nm} / \mathrm{min}$, (b) $T_{\text {sub }}=650^{\circ} \mathrm{C}$ and $R=64 \mathrm{~nm} / \mathrm{min}$, (c) $T_{\text {sub }}=550^{\circ} \mathrm{C}$ and $R=840 \mathrm{~nm} / \mathrm{min}$, and (d) $T_{\text {sub }}=550^{\circ} \mathrm{C}$ and $R=64 \mathrm{~nm} / \mathrm{min}$. The X-ray incidence angle is $3.8^{\circ}$. Theoretical $2 \theta-\theta$ patterns of barium silicide phases are also displayed below the experimental patterns. 
You may notice that the $\mathrm{BaSi}_{2}$ formation temperature is slightly different from our previous works. ${ }^{5,20,21}$ This is because we used a different evaporator from previous one. There are many differences between the two evaporators such as chamber size, substrate heater, and the source-substrate distance. At present, we cannot identify the factor influencing the $\mathrm{BaSi}_{2}$ formation window. Our future study on $\mathrm{BaSi}_{2}$ evaporation may provide hints to understand it.

The film thickness also changes with $R$. Figure 2(a) shows the thickness of evaporated films deposited at $T_{\text {sub }}=650^{\circ} \mathrm{C}$ as a function of $R$. Film thickness was measured by crosssectional SEM, one example of which $\left(T_{\text {sub }}=650^{\circ} \mathrm{C}\right.$ and $R=840 \mathrm{~nm} / \mathrm{min}$ ) is shown in the inset of Fig. 2. The film thickness is found to increase with increasing $R$. This thickness change is because the evaporation amount changes by source heating current. As we reported previously, a part of source remains on the boat after evaporation, and the residue consists solely of Si atoms. ${ }^{5}$ The percentage of residual source is displayed in Fig. 2(b). The amount of source residue clearly decreases with $R$, corresponding to the increase of vapor. This result well explains the difference of film thickness.

The above results can be well explained on the basis of the $\mathrm{BaSi}_{2}$ film formation mechanism previously proposed by us. ${ }^{5,20,22,23}$ In the $\mathrm{BaSi}_{2}$ evaporation process, the vapor composition is Ba-rich in average ${ }^{5}$ and, in addition, the composition changes with time from Ba-rich to Si-rich. ${ }^{20}$ Diffusion is, therefore, a requisite process for the formation of singlephase $\mathrm{BaSi}_{2}$ films. Under the condition of $T_{\text {sub }}=550^{\circ} \mathrm{C}$ and $R=840 \mathrm{~nm} / \mathrm{min}$, the diffusion time of atoms is probably not enough. This is the reason why we obtained other barium silicide phases. Present results clearly demonstrate the importance of diffusion for the formation of $\mathrm{BaSi}_{2}$ films.

\section{B. Microstructural analysis}

We have further investigated the microstructure of the evaporated $\mathrm{BaSi}_{2}$ films by TEM, XPS, Raman spectroscopy,

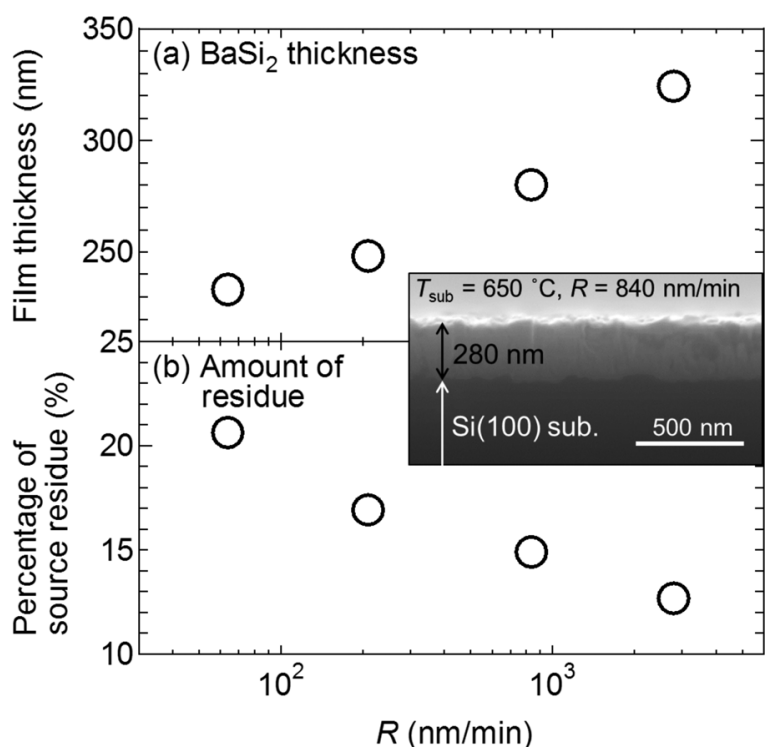

FIG. 2. (a) Film thickness and (b) percentage of source residue as a function of $R . T_{\text {sub }}=650{ }^{\circ} \mathrm{C}$. Inset is an SEM image of the evaporated film deposited at $R=840 \mathrm{~nm} / \mathrm{min}$. SEM was operated at an acceleration voltage of $15 \mathrm{kV}$. and SEM-EDX. Figure 3 shows the cross-sectional TEM images of the films grown at $T_{\text {sub }}=650{ }^{\circ} \mathrm{C}$ and $R=64$ and $840 \mathrm{~nm} / \mathrm{min}$. From the bright- and dark-field images [Figs. 3(a) and 3(b)], it is found that the film grown at $64 \mathrm{~nm} / \mathrm{min}$ has slightly larger grains along a planar direction $(70-120 \mathrm{~nm})$, while the film of $840 \mathrm{~nm} / \mathrm{min}$ is elongated toward the growth direction and the planar size is $30-120 \mathrm{~nm}$. These grain sizes are smaller than the domain sizes of $\mathrm{BaSi}_{2}$ epitaxial films $\left(>4 \mu \mathrm{m}\right.$ with optimized growth conditions ${ }^{24,25}$ and $100-300 \mathrm{~nm}$ at higher template growth rates $\left.^{7}\right)$. By comparing the films between $R=64$ and $840 \mathrm{~nm} / \mathrm{min}$, one can notice that one grain sometimes covers the total depth of the film from the surface to the interface at $R=840 \mathrm{~nm} / \mathrm{min}$ like a columnar structure. On the other hand, no such columnar structure is observed at $R=64 \mathrm{~nm} / \mathrm{min}$. It is known that the microstructure of a film depends on $T_{\text {sub }}$ and $R$. With increasing $T_{\text {sub }}$, microstructure changes from tapered crystallites with voids to columnar grains, and then, recrystallized grains. ${ }^{26-28}$ The temperatures of these transitions are $T_{\text {sub }} / T_{\mathrm{m}}=0.3$ and 0.45 , respectively, where $T_{\mathrm{m}}$ denotes the melting point. Under the present condition of $T_{\text {sub }}=650{ }^{\circ} \mathrm{C}, T_{\text {sub }} / T_{\mathrm{m}}=0.64$, which indicates a microstructure with recrystallized grains. This is consistent with the observed structure at $R=64 \mathrm{~nm} / \mathrm{min}$. It is also reported that, by increasing $R$, the transition temperature increases. ${ }^{29}$ Partial columnar growth at $R=840 \mathrm{~nm} / \mathrm{min}$ may therefore be owing to the enhancement of the transition temperature. One can also notice the film consists mostly of three layers with different grains at $R=64 \mathrm{~nm} / \mathrm{min}$. This is probably because the vapor was intermittently provided to the substrate in correspondence with the evaporation of individual granule. Another notable point is the wavy $\mathrm{BaSi}_{2} / \mathrm{Si}$ interfaces, which agrees with the interdiffusion between the deposited atoms and the substrate. ${ }^{5,20}$

HAADF-STEM images are displayed in Fig. 3(c), which show the homogeneity of composition in most part of the films. Around the interface, however, arrays of white particles (indicated by arrows) are noticed, which presumably consist of different compounds from $\mathrm{BaSi}_{2}$.

This particle array was further investigated by XPS. Figure 4 shows the depth profiles of XPS spectra of Ba $3 d$, Si $2 p$, and $\mathrm{O} 1 s$ core levels and calculated elemental composition. The Ba $3 d$ core-level peak is strong until a sputter time of $132 \mathrm{~min}$, while it diminishes after that. On the other hand, Si $2 p$ peak becomes stronger after $132 \mathrm{~min}$, indicating that sputtering reached the $\mathrm{Si}$ substrate. The $\mathrm{O} 1 \mathrm{~s}$ peak appears around the surface until a sputter time of $12 \mathrm{~min}$, suggesting the existence of a surface oxide layer. Since a surface oxide layer is present also on $\mathrm{BaSi}_{2}$ epitaxial films, ${ }^{30,31}$ surface oxidation is possibly a common phenomenon for $\mathrm{BaSi}_{2}$ films. It should be noted here that the $\mathrm{O} 1 s$ peak is observed when $132 \mathrm{~min}$ of sputtering. This sputter time corresponds to the bottom part of the $\mathrm{BaSi}_{2}$ film. To clearly show the depth, atomic fractions are displayed in Fig. 4(d) as a function of sputter time. A slight increase of $\mathrm{O}$ content is observed in the bottom part of the film, as indicated by a dotted ellipse. This increase of $\mathrm{O}$ proportion agrees well with the HAADF-STEM image with an array of white particles [Fig. 3(c)]. Mean atomic number per volume of $\mathrm{BaO}$ (1.51 $\left.\AA^{-3}\right)$ is larger than $\mathrm{BaSi}_{2}\left(0.97 \AA^{-3}\right)$, which also agrees with 
(a) Bright-field TEM
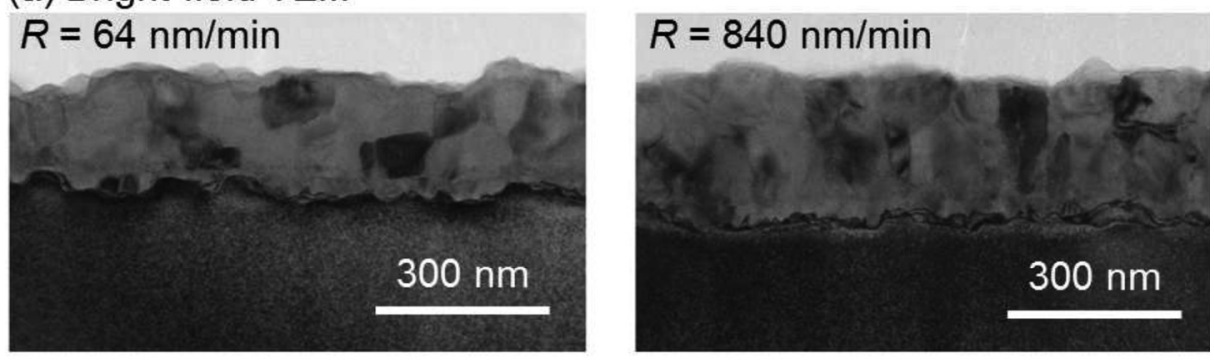

(b) Dark-field TEM
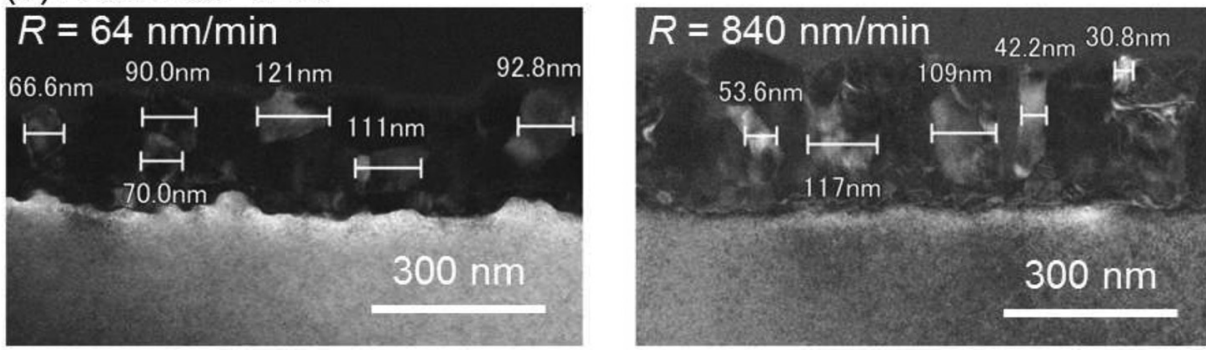

(c) HAADF-STEM

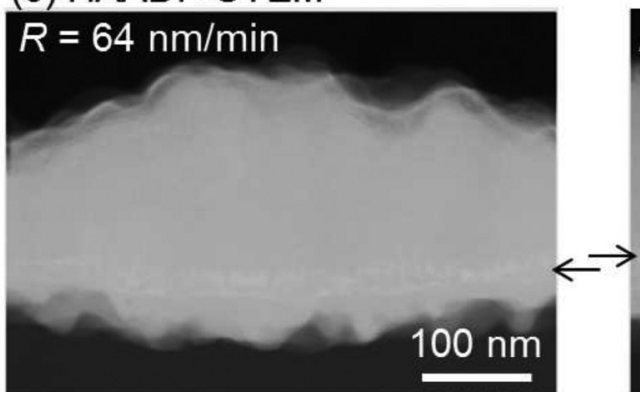

$R=840 \mathrm{~nm} / \mathrm{min}$

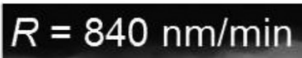

FIG. 3. (a) Bright-, (b) dark-field TEM, and (c) HAADF-STEM images of the cross sections of evaporated $\mathrm{BaSi}_{2}$ films deposited at $T_{\text {sub }}=650^{\circ} \mathrm{C}$ and $R=64$ and $840 \mathrm{~nm} / \mathrm{min}$.
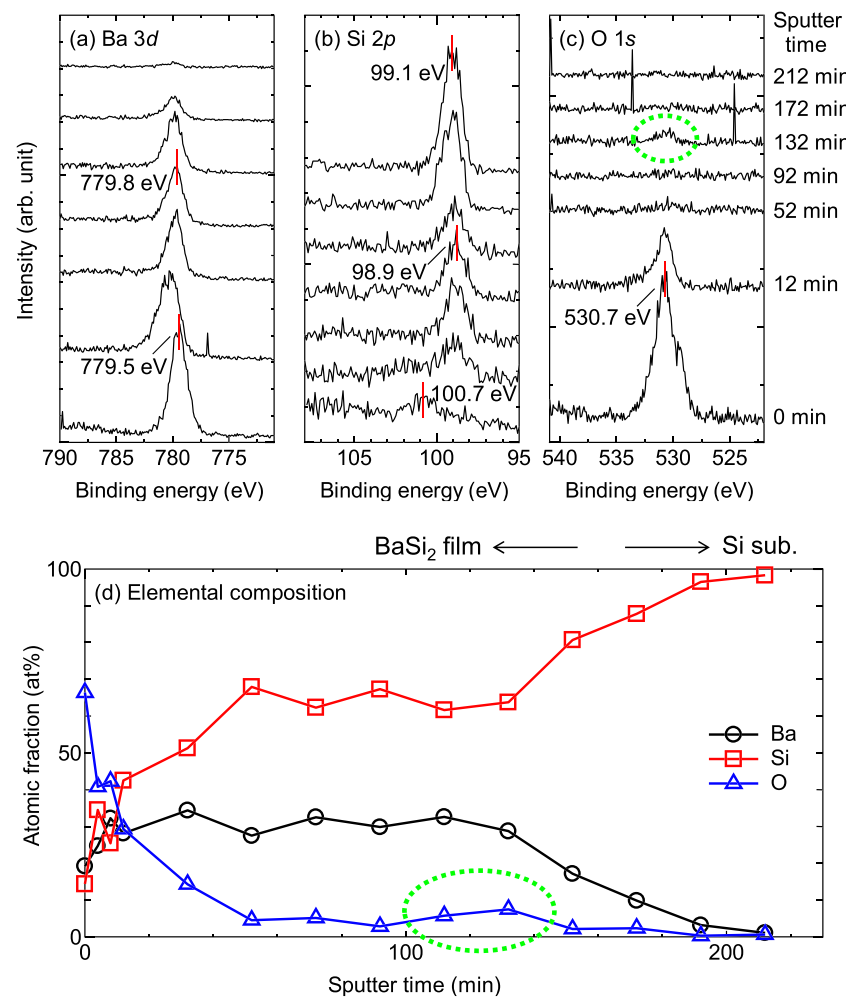

FIG. 4. Depth profiles of XPS spectra of (a) Ba 3d, (b) Si $2 p$, and (c) O $1 s$ core levels in evaporated $\mathrm{BaSi}_{2}$ films deposited at $T_{\text {sub }}=650^{\circ} \mathrm{C}$ and $R=64 \mathrm{~nm} / \mathrm{min}$, and (d) corresponding profiles of atomic fraction. the bright HAADF contrast of particles. The array of particles in the bottom of the film is, therefore, an oxide particle array.

The oxygen atoms in the oxide particle array are possibly from the surface oxide layer of the $\mathrm{BaSi}_{2}$ source, which will be removed in our next study. These oxide particles would affect the crystal orientation of $\mathrm{BaSi}_{2}$ films. In fact, the relative XRD intensity of present $\mathrm{BaSi}_{2}$ films is different from previous ones. ${ }^{20}$

Chemical shifts of $\mathrm{Ba} 3 d$ and $\mathrm{Si} 2 p$ around the surface are also noticed in the XPS spectra. This is presumably due to surface oxidation. The most prominent one is the $\mathrm{Si} 2 p$ peak at $100.7 \mathrm{eV}$, which is different from the inside of the film $(98.9 \mathrm{eV})$ and the substrate $(99.1 \mathrm{eV})$. The peak position of $100.7 \mathrm{eV}$ is also different from the reference position for $\mathrm{SiO}_{2}(103.6 \pm 0.4 \mathrm{eV})$. When $\mathrm{SiO}_{x}(x<2)$ is present, however, $\mathrm{Si} 2 p$ core level can take a peak position between $\mathrm{Si}$ $(99.2 \pm 0.4 \mathrm{eV})$ and $\mathrm{SiO}_{2}(103.6 \pm 0.4 \mathrm{eV}){ }^{32,33}$ It is therefore suggested that $\mathrm{Si}$ atoms at the surface take a partially oxidized state.

Crystalline quality was analyzed by Raman spectroscopy. Figure 5(a) shows the Raman spectra of the $\mathrm{BaSi}_{2}$ films grown at $T_{\text {sub }}=650{ }^{\circ} \mathrm{C}$ and $R=64$ and $2800 \mathrm{~nm} / \mathrm{min}$. Five peaks corresponding to the vibration modes of $\mathrm{Si}$ tetrahedral cluster $\left(\left[\mathrm{Si}_{4}\right]^{4-}\right)$ in $\mathrm{BaSi}_{2}{ }^{34}$ are observed. It is noticed that the film grown at a higher $R$ of $2800 \mathrm{~nm} / \mathrm{min}$ shows slightly sharper bands than $R=64 \mathrm{~nm} / \mathrm{min}$. We used the full width at 

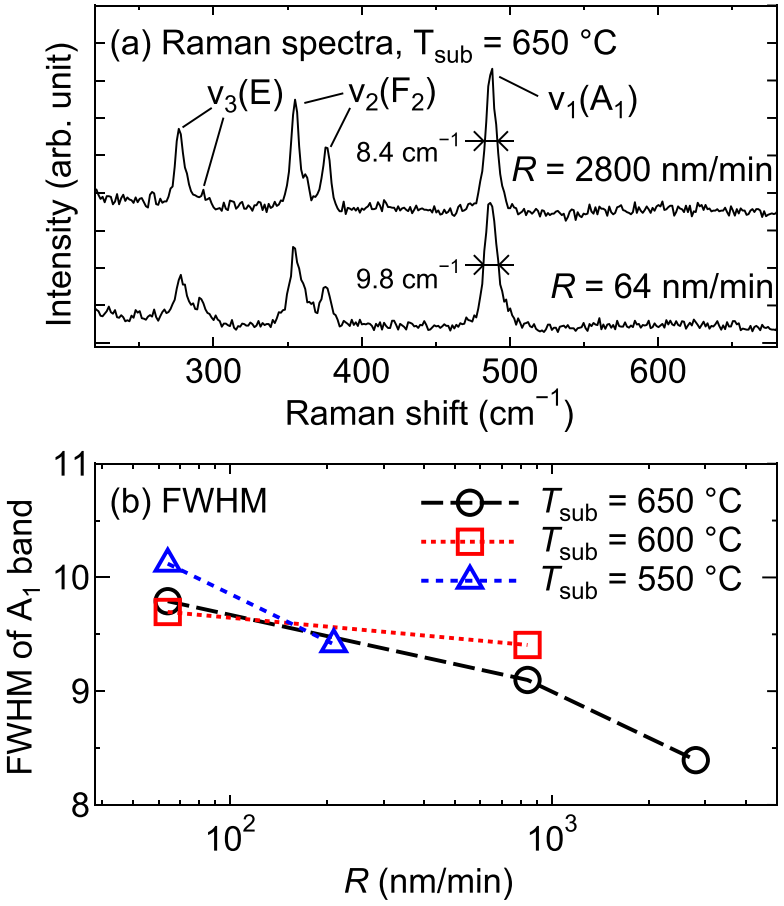

FIG. 5. (a) Raman spectra of the evaporated $\mathrm{BaSi}_{2}$ films deposited at $T_{\text {sub }}=650^{\circ} \mathrm{C}$ and $R=64$ and $2800 \mathrm{~nm} / \mathrm{min}$. (b) FWHM of the $\mathrm{BaSi}_{2} \mathrm{~A}_{1}$ band as a function of $R$.

half-maximum (FWHM) of the $\mathrm{A}_{1}$ mode at $480 \mathrm{~cm}^{-1}$ as an indicator of crystalline quality. The FWHM values are shown in Fig. 5(b) as a function of $R$. It is found that the FWHM value decreases with increasing $R$, which means that the films grown at higher $R$ contain less crystal defects. It is also noticed that $T_{\text {sub }}$ does not have a significant influence on FWHM. These results are apparently not consistent with thermodynamics, which expects lower-energy states close to equilibrium with less defects at high $T_{\text {sub }}$ and low $R$. They can, however, be understood by considering the variation of vapor composition with $R$ and a reaction with the substrate as discussed below.

As shown in Fig. 2(b), the amount of source residue decreases with $R$, meaning that the vapor composition becomes closer to stoichiometric with increasing $R$. The first conceivable mechanism to explain the FWHM variation is the formation of more Ba-rich films at lower $R$, according to the vapor composition. Deviation from stoichiometry would accompany the formation of defects such as Si vacancy. This is, however, not probable when $T_{\text {sub }}$ is sufficiently high. As has been mentioned above, the vapor composition is Ba-rich at the initial stage of evaporation, and it changes to Si-rich as evaporation proceeds. ${ }^{20}$ When $T_{\text {sub }}$ is sufficiently high for the diffusion of $\mathrm{Ba}$ and $\mathrm{Si}$ atoms, initial $\mathrm{Ba}$-rich vapor would react with the Si substrate soon after deposition. Then, Sirich vapor is deposited on the $\mathrm{BaSi}_{2}$ film produced at the initial stage. The $\mathrm{BaSi}_{2}$ films are, therefore, probably more Sirich when $R$ is lower at high $T_{\text {sub. This consideration may }}$ seem to be inconsistent with XPS quantitative analysis result [Fig. 4(d)], which shows lower $\mathrm{Si} / \mathrm{Ba}$ ratio than 2 around the surface. This is presumably because of preferential oxidation of $\mathrm{Ba}$ atoms. Since the surface oxide layer contains more $\mathrm{Ba}$ atoms than the average of film, $\mathrm{Si} / \mathrm{Ba}$ ratio is low around the surface. In accordance with it, $\mathrm{Si} / \mathrm{Ba}$ ratio is slightly high at a sputter time of $52 \mathrm{~min}$. Hence, the $\mathrm{BaSi}_{2}$ films grown at sufficiently high $T_{\text {sub }}$ are probably Si-rich except in surface oxide layers.

At $T_{\text {sub }}=550{ }^{\circ} \mathrm{C}$, where the time for $\mathrm{BaSi}_{2}$ formation through diffusion is comparable to the deposition time, both phenomena should be taken into account. Figure 6 shows cross-sectional SEM images of the films grown at $T_{\text {sub }}=550$ and $650{ }^{\circ} \mathrm{C}$ at $R=64 \mathrm{~nm} / \mathrm{min}$. Since the film grown at $550^{\circ} \mathrm{C}$ contains relatively rough areas, pictures for both the flat and rough areas are shown. EDX spectra were obtained from the point arrays depicted in Fig. 6(a) and elemental composition has been calculated by the ZAF method. Although EDX quantitative analysis is not accurate for oxygen, it is available for relative comparison. Figure 6(b) shows the calculated $\mathrm{O} /$ $\mathrm{Si}$ ratio along the point arrays. The $\mathrm{O} / \mathrm{Si}$ ratio is lower for the film grown at $T_{\text {sub }}=650^{\circ} \mathrm{C}$ especially near the surface than that grown at $T_{\text {sub }}=550{ }^{\circ} \mathrm{C}$. Moreover, the rough area of the $550{ }^{\circ} \mathrm{C}$-grown film contains more oxygen into deeper regions than the flat area. This result indicates that the $\mathrm{BaSi}_{2}$ film grown at $T_{\text {sub }}=550{ }^{\circ} \mathrm{C}$ and $R=64 \mathrm{~nm} / \mathrm{min}$ is partially oxidized around the surface, especially in the rough areas. Since $\mathrm{Ba}$ atoms are more easily oxidized than $\mathrm{Si}$, this film may be Ba-rich due to slow consumption of excess Ba atoms through diffusion at $T_{\text {sub }}=550{ }^{\circ} \mathrm{C}$. The existence of oxides would disturb the crystal structure of the $\mathrm{BaSi}_{2}$ phase, leading to the increase in the FWHM of the $\mathrm{A}_{1}$ band in Raman spectrum, as detected in Fig. 5.

Besides the vapor composition, there are two conceivable factors for the FWHM variation. One is the contamination by oxygen, as detected by HAADF-STEM and XPS in

\section{(a) Cross-sectional SEM images $(R=64 \mathrm{~nm} / \mathrm{min})$}
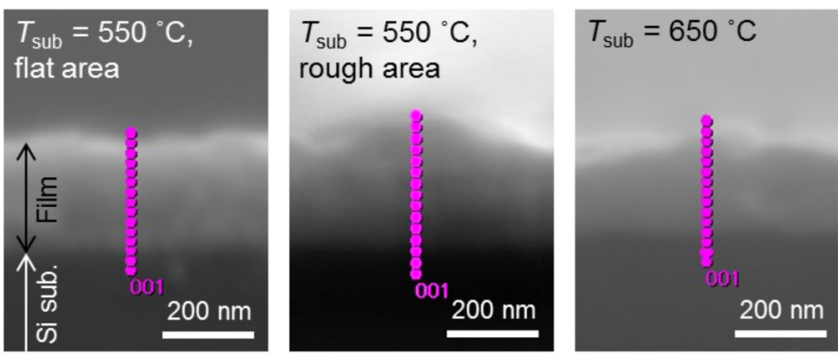

(b) Line profile of O/Si ratio

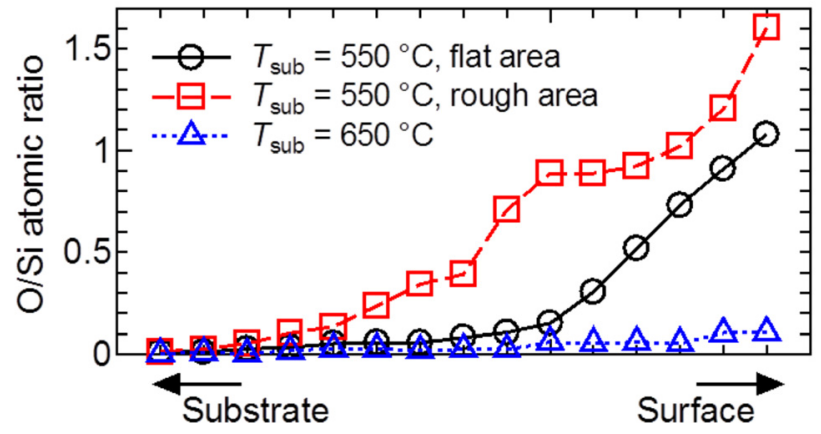

FIG. 6. (a) Cross-sectional SEM images of the $\mathrm{BaSi}_{2}$ films grown at $R=64 \mathrm{~nm} / \mathrm{min}$ and $T_{\text {sub }}=550$ and $650^{\circ} \mathrm{C}$ including the point arrays for EDX scans. Flat and rough areas are shown for $T_{\text {sub }}=550{ }^{\circ} \mathrm{C}$. (b) Line profile of $\mathrm{O} / \mathrm{Si}$ atomic ratio. 
Figs. 3(c) and 4, and by desorbed molecules from the chamber wall. Oxygen contamination is probably not the factor of FWHM decrease with $R$ because the amount of the oxide particles does not seem to significantly vary with $R$, as observed in Fig. 3(c). On the other hand, desorbed molecules can explain the FWHM decrease because evaporation time is shortened as $R$ increases, corresponding to the reduced time of chamber wall heating. Another possible factor is grain size difference. When $R$ is higher, however, grain size along a planar direction is smaller [Fig. 3(b)], which is an opposite tendency to FWHM. Although grain size along the growth direction is larger for higher $R$, it is not detected by our Raman spectroscopy because the penetration depth of $488 \mathrm{~nm}$ laser $(23 \mathrm{~nm})$ is shallower than the grain size $(>80 \mathrm{~nm})$.

Possible mechanisms of the FWHM variation are therefore the composition deviation of films to Si-rich with decreasing $R$ or the contamination. Only when $T_{\text {sub }}$ is low $\left(550^{\circ} \mathrm{C}\right)$, the composition of films can be Ba-rich. This point will be discussed later again with electrical properties.

\section{Electrical properties}

Electrical properties of evaporated $\mathrm{BaSi}_{2}$ films were investigated by Hall measurement. All films exhibited n-type conductivity. Figure 7(a) shows the electron density $(n)$ of the $\mathrm{BaSi}_{2} / \mathrm{Si}$ samples as a function of $R$. Four sets of data with different substrate temperatures and resistivities, and speculation are shown. First of all, it should be noted that $n$ decreases with increasing $R$. This tendency agrees with the FWHM of $A_{1}$ band in Raman spectra (Fig. 5). The possible origin of carriers is, therefore, the crystal defects formed due to nonstoichiometry or contaminant impurities.

Another finding is that the $n$ values are significantly different on low- $(1-30 \Omega \mathrm{cm})$ and high-resistivity $(\geq 1000 \Omega$ $\mathrm{cm}$ ) substrates. When using the low-resistivity substrate, current may leak through the substrate. This hole current would generate the opposite Hall voltage to that of the film. At the same time, electron current flowing through the film is reduced, which suppresses the Hall voltage in the film. The (a) Electron density

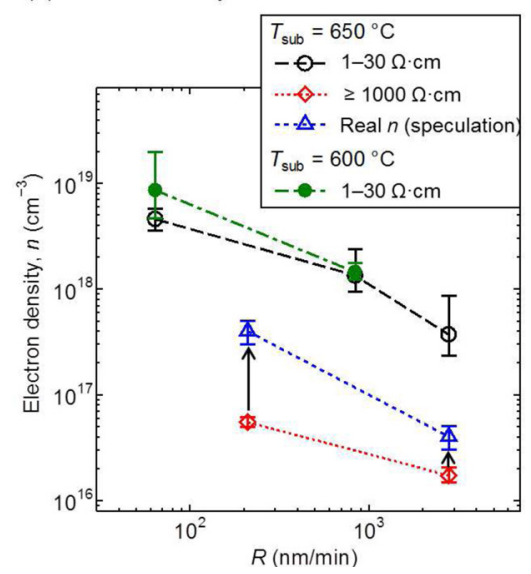

(b) Top-view images

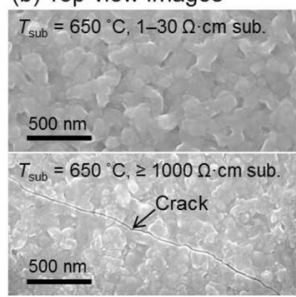

(c) Current flow with cracks

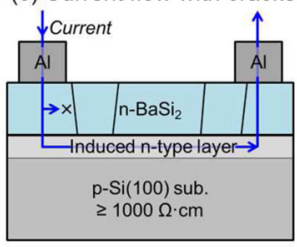

FIG. 7. (a) $n$ of the $\mathrm{BaSi}_{2} / \mathrm{Si}$ samples fabricated at $T_{\text {sub }}=600$ and $650{ }^{\circ} \mathrm{C}$. (b) Top-view SEM images of the films grown on low- $(1-30 \Omega \mathrm{cm})$ and highresistivity $(\geq 1000 \Omega \mathrm{cm})$ substrates at $T_{\text {sub }}=650^{\circ} \mathrm{C}$ and $R=2800 \mathrm{~nm} / \mathrm{min}$. (c) Schematic drawing of current flow path during the Hall measurement on cracked samples. overall Hall voltage is accordingly reduced due to leakage. Since carrier density is inversely proportional to the Hall coefficient, therefore, carrier density is possibly overestimated on the low-resistivity substrate. This consideration is consistent with the observed high $n$ values with the lowresistivity substrate.

From the above considerations, the $n$ values when using the high-resistivity substrate seem to be more accurate. Under the present growth condition, however, the films grown on the high-resistivity substrate suffered from cracking, as shown in Fig. 7(b). The reason of cracking is still not clear. A conceivable factor is thermal stress, which is reported for $\mathrm{BaSi}_{2}$ epitaxial films grown on $\mathrm{Si}$ substrates. ${ }^{35}$ With the low-resistivity substrate, boron impurity may have played as a surfactant during the $\mathrm{BaSi}_{2}$ growth, through which cracking may have been suppressed. Surfactant effects of B impurity are reported for $\mathrm{Si}$ and Ge growth. ${ }^{36,37}$ Despite cracking of films on the high-resistivity substrate, the sample shows negative Hall voltages. This is the evidence of the existence of an n-type layer in the Si substrate near the interface as depicted in Fig. 7(c). This induced n-type Si layer is formed because of a lower electron affinity of n-type $\mathrm{BaSi}_{2}$ $(3.2 \mathrm{eV})^{38}$ than p-type $\mathrm{Si}(4.0 \mathrm{eV})$, as discussed in our previous publications on impurity doping of $\mathrm{BaSi}_{2}$ films. ${ }^{14-16}$ Using such cracked films, we cannot detect the Hall voltage in the film, but only that in the induced n-type layer. The obtained $n$ values are, therefore, underestimated on the highresistivity substrate.

Assuming that the $\mathrm{BaSi}_{2} / \mathrm{Si}$ interface is perfect so that no Fermi level pinning occurs, we can speculate the real $n$ values in the film from those in the induced n-type layers using the high-resistivity substrate data. We used the wxAMPS software ${ }^{39}$ to simulate the distribution of electron density $\left(n_{\text {sub }}\right)$ in the substrate with an arbitrary $n$ value in the film. When the $n_{\text {sub }}$ value averaged over the substrate thickness agrees with an experimental $n$ value, the input $n$ value was adopted as the presumable real $n$ value. Thus, speculated $n$ values are displayed by blue triangles in Fig. 7(a). These values are smaller than those of the low-resistivity substrates, which agrees with the above consideration of overestimation of $n$ with low-resistivity substrates.

Figure 8 shows $n$ of the $\mathrm{BaSi}_{2} / \mathrm{Si}$ samples fabricated at $T_{\text {sub }}=550^{\circ} \mathrm{C}$ with the low-resistivity $(1-30 \Omega \mathrm{cm})$ substrates. The films grown at $R \geq 200 \mathrm{~nm} / \mathrm{min}$ show high $n$ values over $10^{22} \mathrm{~cm}^{-3}$. This is presumably resulted from the

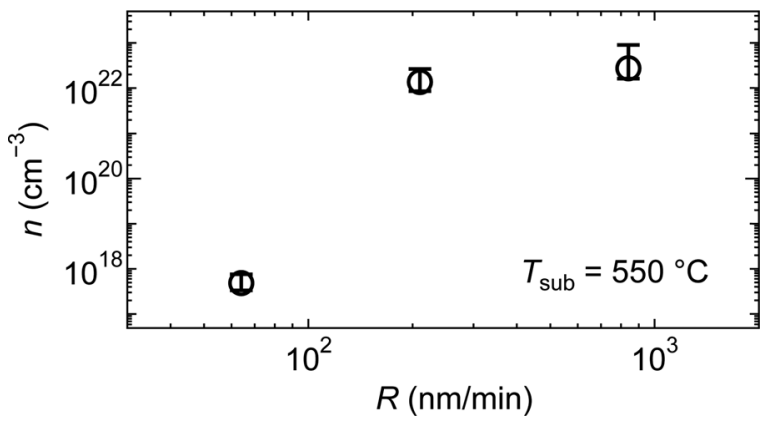

FIG. 8. $n$ of the $\mathrm{BaSi}_{2} / \mathrm{Si}$ samples with low-resistivity $(1-30 \Omega \mathrm{cm})$ substrates fabricated at $T_{\text {sub }}=550{ }^{\circ} \mathrm{C}$. 
coexistence of metallic phases such as $\mathrm{BaSi}^{40}$ with $\mathrm{BaSi}_{2}$, as revealed by XRD in Fig. 1.

It should also be noted that, at $R=64 \mathrm{~nm} / \mathrm{min}, n$ is lower $\left(5 \times 10^{17} \mathrm{~cm}^{-3}\right)$ at $T_{\text {sub }}=5500^{\circ} \mathrm{C}$ than at $650{ }^{\circ} \mathrm{C}\left(5 \times 10^{18}\right.$ $\mathrm{cm}^{-3}$ ). This tendency cannot be explained by contamination with desorbed molecules because the amount of desorption would not depend on $T_{\text {sub }}$. On the other hand, this $T_{\text {sub }}$ dependence is consistent with the consideration of nonstoichiometry. As discussed on the basis of the Raman spectroscopy (Fig. 5) and SEM-EDX (Fig. 6) results, the $\mathrm{BaSi}_{2}$ film grown at $T_{\text {sub }}=550{ }^{\circ} \mathrm{C}$ can be Ba-rich due to suppressed diffusion, and the excess $\mathrm{Ba}$ atoms are oxidized. If the excess $\mathrm{Ba}$ atoms are partly extracted from the Ba-rich $\mathrm{BaSi}_{2}$ phase by oxidation, the $\mathrm{BaSi}_{2}$ phase becomes close to stoichiometric, where carrier density is expected to be reduced. Thus, lower $n$ at $T_{\text {sub }}=550{ }^{\circ} \mathrm{C}$ is possibly because of suppressed composition deviation from stoichiometry.

In summary, we have found that electron density in evaporated $\mathrm{BaSi}_{2}$ films decreases with increasing $R$ when deposited at sufficiently high $T_{\text {sub }}$. This is probably because of the composition deviation to Si-rich at low $R$. When $T_{\text {sub }}$ is low for diffusion of $\mathrm{Ba}$ and $\mathrm{Si}$, the film can be Ba-rich, and the excess $\mathrm{Ba}$ atoms are partly extracted from the $\mathrm{BaSi}_{2}$ phase by oxidation, which leads to low carrier density. The present findings are essential for the control of electrical properties of evaporated $\mathrm{BaSi}_{2}$ films, and can open the way to solar cell and other electronic devices using evaporated $\mathrm{BaSi}_{2}$ films.

\section{CONCLUSION}

We have investigated the effects of $R$ on the produced phases, microstructure, and electrical properties of the thin films fabricated by thermal evaporation of $\mathrm{BaSi}_{2}$. It has been found that a high $T_{\text {sub }}$ is necessary for high-speed fabrication of $\mathrm{BaSi}_{2}$ films. When $T_{\text {sub }}$ is low, subsilicides such as BaSi and $\mathrm{Ba}_{5} \mathrm{Si}_{3}$ coexist with $\mathrm{BaSi}_{2}$ at high $R$ because of insufficient diffusion time. The present 230-330-nm-thick $\mathrm{BaSi}_{2}$ films grown at $T_{\text {sub }}=650{ }^{\circ} \mathrm{C}$ consist of crystal grains of $30-120 \mathrm{~nm}$ and include oxide particle arrays in the bottom part. As evidenced by the FWHM of the $\mathrm{A}_{1}$ vibration mode in Raman spectra, crystalline quality improves with increasing $R$ mainly because the composition deviation of $\mathrm{BaSi}_{2}$ would be suppressed at high $R$. When $T_{\text {sub }}$ is low, partial oxidation can also enhance the FWHM. Suppressed nonstoichiometry presumably brings about low electron density, which was determined by Hall measurement. This is an important finding for the control of electrical properties of evaporated $\mathrm{BaSi}_{2}$ films.

\section{ACKNOWLEDGMENTS}

This work was partly supported by Core Research for Evolutional Science and Technology (CREST) of the Japan Science and Technology Agency (JST), JSPS KAKENHI Grant No. 15K18040, the Murata Science Foundation, and the Iketani Science and Technology Foundation.

${ }^{1}$ T. Nakamura, T. Suemasu, K. Takakura, F. Hasegawa, A. Wakahara, and M. Imai, Appl. Phys. Lett. 81, 1032 (2002).
${ }^{2}$ S. Kishino, T. Imai, T. Iida, Y. Nakaishi, M. Shinada, Y. Takanashi, and N. Hamada, J. Alloys Compd. 428, 22 (2007).

${ }^{3}$ K. Toh, T. Saito, and T. Suemasu, Jpn. J. Appl. Phys., Part 1 50, 068001 (2011).

${ }^{4}$ N. A. A. Latiff, T. Yoneyama, T. Shibutami, K. Matsumaru, K. Toko, and T. Suemasu, Phys. Status Solidi C 10, 1759 (2013).

${ }^{5}$ K. O. Hara, Y. Nakagawa, T. Suemasu, and N. Usami, Jpn. J. Appl. Phys., Part 1 54, 07JE02 (2015).

${ }^{6}$ K. Morita, Y. Inomata, and T. Suemasu, Thin Solid Films 508, 363 (2006).

${ }^{7}$ M. Baba, K. Toh, K. Toko, N. Saito, N. Yoshizawa, K. Jiptner, T. Sekiguchi, K. O. Hara, N. Usami, and T. Suemasu, J. Cryst. Growth 348, 75 (2012).

${ }^{8}$ K. O. Hara, N. Usami, K. Nakamura, R. Takabe, M. Baba, K. Toko, and T. Suemasu, Appl. Phys. Express 6, 112302 (2013).

${ }^{9}$ M. Kobayashi, K. Morita, and T. Suemasu, Thin Solid Films 515, 8242 (2007).

${ }^{10}$ M. Kobayashi, Y. Matsumoto, Y. Ichikawa, D. Tsukada, and T. Suemasu, Appl. Phys. Express 1, 051403 (2008).

${ }^{11}$ M. A. Khan, M. Takeishi, Y. Matsumoto, T. Saito, and T. Suemasu, Phys. Procedia 11, 11 (2011).

${ }^{12}$ M. A. Khan, T. Saito, K. Nakamura, M. Baba, W. Du, K. Toh, K. Toko, and T. Suemasu, Thin Solid Films 522, 95 (2012).

${ }^{13}$ M. A. Khan, K. Hara, W. Du, M. Baba, K. Nakamura, M. Suzuno, K. Toko, N. Usami, and T. Suemasu, Appl. Phys. Lett. 102, 112107 (2013).

${ }^{14}$ K. O. Hara, Y. Hoshi, N. Usami, Y. Shiraki, K. Nakamura, K. Toko, and T. Suemasu, Thin Solid Films 557, 90 (2014).

${ }^{15}$ K. O. Hara, N. Usami, M. Baba, K. Toko, and T. Suemasu, Thin Solid Films 567, 105 (2014).

${ }^{16}$ K. O. Hara, W. Du, K. Arimoto, J. Yamanaka, K. Nakagawa, K. Toko, T. Suemasu, and N. Usami, Thin Solid Films 603, 218 (2016).

${ }^{17}$ T. Suemasu, Jpn. J. Appl. Phys., Part 1 54, 07 JA01 (2015).

${ }^{18}$ Y. Inomata, T. Nakamura, T. Suemasu, and F. Hasegawa, Jpn. J. Appl. Phys., Part 2 43, L478 (2004).

${ }^{19}$ K. Toh, K. O. Hara, N. Usami, N. Saito, N. Yoshizawa, K. Toko, and T. Suemasu, J. Cryst. Growth 345, 16 (2012).

${ }^{20}$ Y. Nakagawa, K. O. Hara, T. Suemasu, and N. Usami, Jpn. J. Appl. Phys., Part 1 54, 08KC03 (2015).

${ }^{21}$ K. O. Hara, J. Yamanaka, K. Arimoto, K. Nakagawa, T. Suemasu, and N. Usami, Thin Solid Films 595A, 68 (2015).

${ }^{22}$ Y. Nakagawa, K. O. Hara, T. Suemasu, and N. Usami, Procedia Eng. 141, 23 (2016).

${ }^{23}$ K. O. Hara, K. Nakagawa, T. Suemasu, and N. Usami, Procedia Eng. 141, 27 (2016).

${ }^{24}$ M. Baba, K. Nakamura, W. Du, M. A. Khan, S. Koike, K. Toko, N. Usami, N. Saito, N. Yoshizawa, and T. Suemasu, Jpn. J. Appl. Phys., Part 1 51, 098003 (2012).

${ }^{25}$ M. Baba, K. Toh, K. Toko, K. Hara, N. Usami, N. Saito, N. Yoshizawa, and T. Suemasu, J. Cryst. Growth 378, 193 (2013).

${ }^{26}$ B. A. Movchan and A. V. Demchishin, Fiz. Met. Metalloved. 28, 653 (1969).

${ }^{27}$ J. A. Thornton, J. Vac. Sci. Technol. 12, 830 (1975).

${ }^{28}$ I. Petrov, P. Barna, L. Hultman, and J. Greene, J. Vac. Sci. Technol., A 21, S117 (2003).

${ }^{29}$ K.-H. Müller, J. Appl. Phys. 58, 2573 (1985).

${ }^{30}$ R. Takabe, K. O. Hara, M. Baba, W. Du, N. Shimada, K. Toko, N. Usami, and T. Suemasu, J. Appl. Phys. 115, 193510 (2014).

${ }^{31}$ R. Takabe, W. Du, K. Ito, H. Takeuchi, K. Toko, S. Ueda, A. Kimura, and T. Suemasu, J. Appl. Phys. 119, 025306 (2016).

${ }^{32}$ F. Himpsel, F. McFeely, A. Taleb-Ibrahimi, J. Yarmoff, and G. Hollinger, Phys. Rev. B 38, 6084 (1988).

${ }^{33}$ R. Alfonsetti, G. De Simone, L. Lozzi, M. Passacantando, P. Picozzi, and S. Santucci, Surf. Interface Anal. 22, 89 (1994).

${ }^{34}$ M. Somer, Z. Anorg. Allg. Chem. 626, 2478 (2000).

${ }^{35}$ K. O. Hara, N. Usami, K. Nakamura, R. Takabe, M. Baba, K. Toko, and T. Suemasu, Phys. Status Solidi C 10, 1677 (2013).

${ }^{36}$ C.-C. Cho, H.-Y. Liu, L. Magel, and J. Anthony, Appl. Phys. Lett. 63, 3291 (1993)

${ }^{37}$ C. Wang, B. Muller, E. Bugiel, T. Wietler, M. Bierkandt, K. Hofmann, and P. Zaumseil, J. Vac. Sci. Technol., A 22, 2246 (2004).

${ }^{38}$ T. Suemasu, K. Morita, M. Kobayashi, M. Saida, and M. Sasaki, Jpn. J. Appl. Phys., Part 2 45, L519 (2006).

${ }^{39}$ Y. Liu, Y. Sun, and A. Rockett, Sol. Energy Mater. Sol. Cells 98, 124 (2012).

${ }^{40}$ J. Evers and A. Weiss, Solid State Commun. 17, 41 (1975). 